\title{
EVALUATION OF THE THERAPEUTIC EFFECT OF TOPICAL CALCIPOTRIOL VERSUS TOPICAL TRETINOIN IN TREATMENT OF ORAL LEUKOPLAKIA AND THEIR EFFECT ON CLINICAL IMPROVEMENT AND SALIVARY LEVEL OF MMP-9, IL-6 AND TGF- $\beta$ : A RANDOMIZED CLINICAL TRIAL
}

\author{
Dalia M. Ghalwash*, Enji A. Mahmoud*** and Olfat G. Shaker**
}

\begin{abstract}
Background: Leukoplakia is the most common potentially malignant lesion of the oral cavity. The main objective in treatment of oral leukoplakia is to prevent malignant transformation. Retinoids and vitamin D analogues have anti-keratinizing and immunomodulatory properties and proven effectiveness in the treatment of leukoplakia.
\end{abstract}

Aim of the study: the aim of this clinical trial was to compare the effectiveness of topical calcipotriol versus topical tretinoin in treatment of oral leukoplakia regarding changes in clinical score as well as salivary IL-6, TGF- $\beta$ and MMP-9 levels.

Methodology: 40 patients with oral leukoplakia were randomly assigned into two groups. Group 1: (n=20) patients were treated with topical calcipotriol gel applied twice daily for 4 weeks. Group 2: $(n=20)$ patients were treated with topical tretinoin cream applied twice daily for 4 weeks. Clinical improvement as well as salivary level of TGF- $\beta$, IL- 6 and MMP-9 was evaluated 4 weeks after treatment and compared to baseline values.

Results: Both treatments resulted in clinical improvement with no significant differences between groups. However, calcipotriol produced a highly statistically significant reduction in salivary IL-6 and MMP-9 compared to tretinoin while both treatments caused significant reduction in salivary TGF- $\beta$ with no significant difference.

Conclusion: Calcipotriol could be considered a promising therapeutic alternative with fewer side effects for the treatment of oral leukoplakia.

KEYWORDS: Leukoplakia, Calcipotriol, Tretinoin, MMP-9, IL-6, TGF- $\beta$.

\footnotetext{
* Associate Professor of Oral Medicine and Periodontology, Faculty of Dentistry. The British University in Egypt. ** Associate Professor of Oral Medicine and Periodontology, Faculty of Dentistry. Cairo University.

*** Professor of Biochemistry, Faculty of Medicine. Cairo University.
} 


\section{INTRODUCTION}

Oral leukoplakia is one of the most common potentially malignant lesions ${ }^{(\mathbf{1})}$. Leukoplakia was defined by WHO in (2005) as "a white plaque of questionable risk having excluded (other) known diseases or disorders that carry no increased risk for cancer ${ }^{(2)}$. According to the systematic review conducted by Petti ${ }^{(3)}$, the estimated prevalence rate of leukoplakia was found to be $2 \%$ worldwide. Leukoplakia lesions are most common in the buccal mucosa, floor of the mouth, tongue, lip and vermilion border and have a high risk of malignant potential ${ }^{(4)}$.

Rate of malignant transformation of oral leukoplakia has an average of $1 \%$ of cases per year ${ }^{(5)}$. Factors blamed to be responsible for higher risk of malignant transformation are: female gender, nonsmokers, speckled or proliferative leukoplakia and presence of epithelial dysplasia. However, cases of malignant transformation of leukoplakia have been reported in the absence of the above mentioned factors ${ }^{(6-8)}$.

It's well recognized that numerous proinflammatory cytokines besides being regulators of the inflammatory response, have an important role in oral diseases and their level was reported to be increased in patients with potentially malignant lesions and oral cancer, one of such cytokines is Interleukin-6 (IL-6) ${ }^{(9)}$.

Interleukin-6 (IL-6) is a multifunctional cytokine that was reported to be involved together with its downstream targets in the regulation of cell proliferation, survival, and metabolism, IL-6 signalling has also been implicated in malignant transformation and tumorigenesis ${ }^{(\mathbf{1 0})}$. IL-6 expression has shown to be induced by the transcription factor NF- $x \mathrm{~B}$ under hypoxic conditions which is correlated with aggressive tumor growth and poor patient prognosis ${ }^{(11)}$. This detrimental effect of hypoxia has been attributed to an increase in the level of hypoxia inducible factor- $1 \alpha$. The latter one is mediated through the downstream signalling element of IL-6 pathway - the STAT3 ${ }^{(12)}$. STAT3 regulates $\mathrm{G} 1$ to $\mathrm{S}$ cell-cycle progression as well as the prevention of apoptosis. Thus, the IL-6/gp130/ STAT3 axis has been implicated in playing a crucial role in the sequential change from hyperplasia to neoplasia ${ }^{(13,14)}$.

Brailo et al., (15) reported that patients with oral leukoplakia have significantly higher level of salivary IL-6 compared to healthy control.They suggested that this increase might be due to local production of IL-6 that may have two sources: either from the lesional epithelium itself or from lymphocytes of a discrete chronic inflammatory infiltrate present in tissues affected with leukoplakia.

The expression of growth factors and their receptors are thought to play a crucial role in the malignant transformation and tumor progression ${ }^{(16)}$. Transforming growth factors (TGFs) are involved in normal growth and differentiation of oral keratinocytes ${ }^{(17)}$. Transforming growth factor $\beta 1$ (TGF- $\beta 1$ ) is a member of a highly pleiotropic family of growth factors. Their signalling pathway has multiple and diverse roles in epithelial-type cells. In precancerous lesions and during the early stages of tumor progression, TGF- $\beta 1$ was found to exert tumor-suppressive effects. While during the later stages of cancer, TGF- $\beta 1$ signalling was reported to promote tumor growth and invasion ${ }^{(18)}$. Understanding the mechanisms behind the role of TGF- $\beta 1$ in oral cancer is vital for identifying novel targets for pharmacological intervention ${ }^{(\mathbf{1 9})}$.

Matrix metallo-proteinases (MMPs) a group of enzymes secreted by macrophages, neutrophils and fibroblasts in response to the stimulus from TGF- $\beta$ and IL- 8 and are responsible for the degradation of most extracellular matrix proteins during organogenesis, growth and normal tissue turnover. The secreted MMPs maintain the growth factors bioavailable which results in cancer proliferation ${ }^{(20)}$. Among many factors included in etiopathogenesis 
of potentially malignant disorders as leukoplakia, MMP-9 plays a main role in tumorigenesis ranging from initiation/promotion to angiogenesis, dissemination, immunological surveillance and metastatic growth. Tissue damage due to excessive proteolytic activity is a common consequence of sustained expression of MMP-9 (21,22).

Generally, the main objective in treatment of oral leukoplakia is to prevent malignant transformation which requires adequate knowledge about nature of the disease and careful evaluation of the case ${ }^{(23)}$.

In cases with moderate to severe epithelial dysplasia where there is high risk for malignancy, surgical removal is recommended ${ }^{(24)}$. While in low to moderate epithelial dysplasia , non-surgical treatment should be considered with the advantage of less adverse reactions, less invasion, ease of application and relative low cost, especially, when oral leukoplakia affects large area or in patients with medical condition contraindicating surgical management ${ }^{(6,25,24)}$.

Retinoic acid (Vitamin A) and Vitamin D analogue both were examined in treatment of oral leukoplakia and has shown efficacy (23, 26-29).

Topical retinoids such as tretinoin are used as offlabel drugs in some oral pathologies after addition of a mucosal adhesive paste (Orabase) to improve their adherence and retention to the oral mucosa ${ }^{(30)}$. The ability of retinoids to regulate growth, differentiation, proliferation and apoptosis of cells together with their effect in modulating MMP-9 expression explains their efficacy in suppressing tumor formation in many cancers ${ }^{(31-33)}$.

Calcitriol or vitamin D3 is a well-known prodifferentiating hormone that regulates the activity of more than 60 genes involved in cell differentiation and inducing the expression of adhesion proteins. These effects are potentially therapeutic as these adhesion proteins have the ability to maintain cell bonding preserving tissue integrity ${ }^{(34)}$. Calcipotriol or calcipotriene is a synthetic analogue of calcitriol or vitamin D3 ${ }^{(35)}$.

Calcipotriol has proved efficacy in treatment of hyperkeratotic skin lesions such as psoriasis. The therapeutic potential of topical calcipotriol in hyperkeratotic lesions relay on its antiproliferative and anti-inflammatory effect. The use of calcipotriol in treatment of precancerous and cancerous lesions has gained interest since many tissues express vitamin D receptor as well as vitamin D metabolizing enzymes. Thus, it inhibits proliferation and stimulates differentiation of normal as well as malignant cells ${ }^{(36)}$.

Modulation of cellular differentiation and proliferation by compounds such as some of the newer retinoids and calcipotriol offers the possibility for the therapeutic prevention, reversal, or arrest of carcinogenesis ${ }^{(23)}$.

Therefore, the aim of this clinical trial was to compare the effectiveness of topical calcipotriol versus topical tretinoin in treatment of oral leukoplakia regarding changes in clinical score as well as salivary IL-6, TGF- $\beta$ and MMP-9 levels.

\section{SUBJECTS AND METHODS:}

Study design: This study is a parallel group, two arms, Randomized Controlled Trial (RCT) with 1:1 allocation ratio.

Patient selection: The present study was performed on a total of 40 subjects having oral leukoplakia (OL) selected from the outpatient clinic of oral medicine \& periodontology Department Faculty of Oral and Dental Medicine, Cairo University, Cairo-Egypt.

\section{Eligibility criteria for patients' selection:}

\section{Inclusion criteria included:}

1. Systemically free patients as evaluated by the aid of dental modification of the Cornell Medical Index to standardize their systemic condition ${ }^{(37)}$. 
2. Patients with oral leukoplakia, histologically confirmed, with only mild or moderate epithelial dysplasia.

3. Lesions located at sites where the patients could readily apply a topical drug and anticipate that it could remain localized for several minutes ${ }^{(23)}$.

4. Patients willing and able to return for multiple follow up visits.

\section{Exclusion criteria included:}

1. Presence of any visible oral lesions other than leukoplakia.

2. Leukoplakia on soft palate due to difficult accessibility in topical drug application.

3. Periodontitis patients: since chronic periodontitis may affect salivary IL- 6 , TGF- $\beta$ and MMP-9 level ${ }^{(38,39)}$.

4. Contraindications for the use of calcipotriol ${ }^{(40)}$.

5. History of topical and/or systemic therapy for 2 months before the start of study ${ }^{(41)}$.

Ethical procedures: The study was approved by the Research Ethics Committee of Faculty of Dentistry, Cairo University. Each patient was informed about the detailed procedure and both benefits of the treatment and the known side effects and follow-up appointments needed. Each subject participating in the study signed an informed written consent form.

Preoperative patient evaluation: was done as follows:

(i) Case history: Comprehensive oral diagnosis was carried out using the department's oral diagnosis chart. For each patient reviewed, the age at presentation, gender, chief complaint, if there was previous treatments for the chief complaint in more than a month, current medications if any.

Complete medical history was taken to exclude: Concomitant use of vitamin D or calcium or any other drug that can affect calcium homeostasis, conditions contraindicated for the use of calcipotriol $^{(40)}$ such as: a. Hypercalcemia and hypercalciuria, b.
Urolithiasis, c. Parathyroid disease, d. Disorders of calcium metabolism, and e. Pregnancy and lactation

Patients were asked to perform the following laboratory tests: Urea and electrolytes; liver function and haematological status (Complete Blood Count).

(ii) Clinical examination: included examinations of intraoral soft tissue.

A provisional diagnosis of leukoplakia is made as oral leukoplakia implies only the clinical feature of a persistent, adherent white plaque that cannot be rubbed off, that needs to be distinguished from other predominantly white keratotic lesions including frictional keratosis and stomatitis nicotina, which do not have malignant potential ${ }^{(5)}$.

Histopathological examination: The definitive diagnosis of oral leukoplakia was established by histopathological exclusion of other keratotic oral lesions that are recognized as specific entities, and by exclusion of any aetiological agents other than tobacco/areca nut use ${ }^{(42-45,5)}$. Microscopically, there is simple orthokeratosis, or parakeratosis with epithelial hyperplasia and minimal inflammation, or hyperkeratosis with varying degrees of dysplasia ${ }^{(46)}$.

\section{Assignment of interventions:}

Allocation; Sequence generation, Allocation concealment mechanism and implementation:

Patients of each of study groups were randomly assigned to one of two parallel groups, in 1:1 ratio, to receive either topical calcipotriol (group1) or topical tretinoin (group 2). The method used to generate the random allocation sequence of the participants is a computer-generated list of random numbers. Allocation was done using simple randomization procedure using randomization list sequentially numbered, patient were given serial numbers every patient added to list occupied serial number.

Blinding: Single blinded (Data analyst) while operator and patient were not blinded. 


\section{Interventions:}

Participants in this study were divided into 2 groups as follow: Group 1: $(n=20)$ patients were treated with $50 \mathrm{mcg} / \mathrm{g}$ calcipotriol in an adhesive vehicle (carboxymethyl-cellulose) applied twice daily for 4 weeks ${ }^{(23,40)}$. Group 2: $(n=20)$ patients were treated with $0.05 \%$ Tretinoin cream applied twice daily for 4 weeks (Rouses point pharmaceuticals, LLC by DBT laboratories, San Antonio, USA) ${ }^{(47,23,48)}$.

\section{Calcipotriol $(0.005 \%)$ preparation:}

Topical calcipotriol gel was prepared by a specialist in Faculty of Pharmacy, Cairo University as follows: Using balance 4 digit $10 \mathrm{mg}$ of pure calcipotriol powder (TOCRIS Bioscience Company. UK ) was added to $10 \mathrm{~mL}$ ethanol + water using hot magnetic stir. This was diluted by taking $2 \mathrm{ml}$ from ( $1 \mathrm{ml}$ solution+1 $\mathrm{mg}$ pure drug) and dilute in $10 \mathrm{ml}$ solution thus gives $(200 \mu \mathrm{g} / \mathrm{ml}) .1 \mathrm{ml}$ of this dilution ( $200 \mu \mathrm{g} / \mathrm{ml}$ ) added to $40 \mathrm{gm}$ of $2 \%$ carboxymethyl cellulose powder (Research-lab company, India) this gives dilution of $5 \mu \mathrm{g} / \mathrm{g}$.

Patients were instructed to: 1 . Dry the lesion site with sterile gauze, and apply the therapeutic agent as a cream with a cotton bud. 2 . Leave the agent in situ for at least 15 mins. 3. Try to avoid swallowing the drug. All beverages were avoided for at least $30 \mathrm{~min}$ after the drug application. The treatment was for 4 weeks in each case.

Criteria for discontinuing or modifying intervention: If there was any sign of adverse effects or toxicity other than mild hypercalceamic or hypercalciuric action of calcipotriol.

\section{Clinical Evaluation:}

Lesions were evaluated, recorded photographically and given scores at baseline with regular clinical assessments at 0,2 and 4 weeks for groups 1 and 2 as follows: Clinical score: Clinical scores for roughness \& intensity of whiteness was estimated visually according to Femiano et al., (23) to which the following values were given: 0: Total resolution of lesions. 1: Moderate resolution=reduction of consistence with leveling of the lesion. 2: Minimal change=reduction of consistence without leveling of the lesion. 3: No visible change.

Collection of Salivary Samples: Whole saliva was collected at baseline for groups A, B and C and 4weeks follow up after therapy for groups $\mathrm{A}$ and $\mathrm{B}$, under resting conditions in a quiet room between 8 A.M. and noon, at least $1 \mathrm{~h}$ after food intake. Patients were asked to generate saliva in their mouths and to spit into a wide test tube for $10 \mathrm{~min}$, as previously described Following the collection, the saliva was stored at 4 _C for up to 2 hours, immediately centrifuged at $800 \mathrm{~g}$ at $4^{\circ} \mathrm{C}$ for $10 \mathrm{~min}$ and the resulting supernatant was used for further biochemical analysis ${ }^{(49)}$.

\section{Detection of human IL-6 levels in salivary samples:}

The AssayMax Human IL-6 ELISA kit is designed for detection of IL-6 in human plasma, serum, saliva or cell culture supernatants. This assay employs a quantitative sandwich enzyme immunoassay technique that measures IL-6 in 5 hours. A murine monoclonal antibody specific for human IL-6 has been pre-coated onto a microplate. IL-6 in standards and samples is sandwiched by the immobilized antibody and a biotinylated polyclonal antibody specific for human IL-6, which is recognized by a streptavidin-peroxidase conjugate. All unbound material is then washed away and a peroxidase enzyme substrate is added. The color development is stopped and the intensity of the color is measured. The minimum detectable dose of IL-6 is typically $<10 \mathrm{pg} / \mathrm{ml}$. This assay recognizes both natural and recombinant human IL-6

\section{Detection of human TGF- $\beta$ levels in salivary samples:}

TGF- $\beta 1$ was measured in the sera of all patients using Invitrogen Multispecies TGF- $\beta 1$ kit (catalog \# 
KACL1688/ KAC1689) provided from Biosource, California. The Invitrogen Multispecies TGF- $\beta 1$ kit is a solid phase sandwich Enzyme LinkedImmuno-Sorbent Assay (ELISA). A monoclonal antibody specific for TGF- $\beta 1$ has been coated onto the wells of the microtiter strips provided. Samples, including standards of known TGF- $\beta 1$ content, control specimens, and extracted unknowns, are pipetted into these wells, followed by the addition of a biotinylated second antibody. During the first incubation, TGF- $\beta 1$ antibody binds simultaneously to the immobilized (capture) antibody on one site, and to the solution phase biotinylated antibody on a second site. After removal of excess detection antibody, Streptavidin-Peroxidase (enzyme) is added. This binds to the biotinylated antibody to complete the four-member sandwich. After a second incubation and washing to remove all the unbound enzyme, a substrate solution is added, which is acted upon by the bound enzyme to produce color. The intensity of this colored product is directly proportional to the concentration of TGF- $\beta 1$ present in the original specimen.

Detection of human MMP-9 levels in salivary samples: Quantitation of MMP-9 levels in saliva was done using human MMP-9 ELISA kit provided by affymetrixe. Bioscence. This assay is a quantitative sandwich enzyme immunoassay technique. A monoclonal antibody specific for MMP-9 has been pre-coated onto a microplate. Standards and samples are pipetted into the wells and any MMP-9 present is bound by the immobilized antibody. The unbound substances were removed by washing. The enzymelinked monoclonal antibody specific for MMP-9 is added to all wells. A substrate solution is added to the wells after washing to remove any unbound antibody-enzyme reagent. Color was developed in proportion to the amount of MMP-9 bound in the initial step. The color development is stopped and the intensity of the color is measured by ELISA reader.

\section{Statistical Analysis}

All Data were collected, tabulated and subjected to statistical analysis. Statistical analysis is performed by SPSS in general (version 17), also Microsoft office Excel is used for data handling and graphical presentation. Quantitative variables: were described by the Mean, Standard Deviation (SD), the Range (Maximum - Minimum) and qualitative categorical variables were described by proportions and Percentages. KolmogorovSmirnova and Shapiro-Wilk tests of normality are used to test normality hypothesis of all quantitative variables for further choice of appropriate parametric and non parametrictests. Paired sample $t$ test and Wilcoxon Signed Ranks Test are used for testing Pre -post measurements within the same group while independent sample t test and Mann and Whiteny $U$ test are used for comparing the mean changes between the two groups. The $\mathrm{z}$ statistics is used for hypothesis testing of two proportions, while chi-squared test is used for categorical variables in contingency tables. Significance level is considered at $\mathrm{P}<0.05(\mathrm{~S})$; while for $\mathrm{P}<0.01$ is considered highly significant (HS). Two Tailed tests are assumed throughout the analysis for all statistical tests.

\section{RESULTS}

\section{Results for Clinical Score}

In calcipotriol group patients showing total resolution of lesions were $(0 \%)$ at 2 weeks vs $(25$ $\%)$ at 4 weeks, while patients having moderate resolution were $(20 \%)$ at 2 weeks vs $(30 \%)$ at 4 weeks. Finally, cases with no visible changes were $30 \%$ at 2 weeks vs $10 \%$ at 4 weeks. Accordingly, there was statistically significant higher clinical resolution $(\mathrm{P}<0.05)$ at 4 weeks than 2 weeks for scores 0 and 1 and lower for scores 2 and 3 .

Regarding tretinoin group patients showing total resolution of lesions were $(0 \%)$ at 2 weeks vs 
$(10 \%)$ at 4 weeks, while patients having moderate resolution were $(10 \%)$ at 2 weeks vs $(30 \%)$ at 4 weeks. Finally, cases with no visible changes were $(45 \%)$ at 2 weeks vs (30\%) at 4 weeks. Accordingly, there was statistically significant higher clinical resolution $(\mathrm{P}<0.05)$ at 4 weeks than 2 weeks for scores 0 and 1 and lower for scores 2 and 3 .

When clinical scores were compared between the two groups it was evident that at 2 weeks of treatment no patient showed total resolution of lesion neither in group I nor in group II. However, patients with moderate resolution of lesions were $20 \%$ in group I vs $10 \%$ in group II. Then, the percentage was higher in calcipotriol than in tretinoin treated group but doesn't reach significance (P-value $=0.943$ ). Additionally, patients with minimal change were 50 $\%$ in calcipotriol group vs $45 \%$ in tretinoin group. Then, the percentage of improved cases is slightly higher in calcipotriol group than tretinoin however it doesn't reach significance (P-value $=0.8808$ ). Moreover, there was no visible change in $30 \%$ of calcipotriol vs $45 \%$ in tretinoin treated group which indicates higher percentage of patients with no visible improvement in tretinoin group. However, it is also statistically non-significant (P-value = 0.8808). At 4 weeks of treatment, the percentage of improved cases was slightly higher in calcipotriol than tretinoin group however it didn't reach significance as well (P-value 0.2119) as shown in Table (1).
Comparing cases with any improvement whether total, moderate or minimal improvement versus cases with no visible changes at 4 weeks which is the total follow up period. The improved cases in calcipotriol group were 16 out of 20 representing $80 \%$ and those of tretinoin group were 14 out of 20 equals to $70 \%$. However, cases with no visible changes in calcipotriol group were 2 out of 20 cases representing $10 \%$ compared to 2 out of 20 patients which are $10 \%$ of the tretinoin cases. Accordingly, there is a higher percentage of improved cases compared to non-improved cases in both groups. Generally, there was no statistically significant difference between the two groups with P-value (0.854) Figure (1)

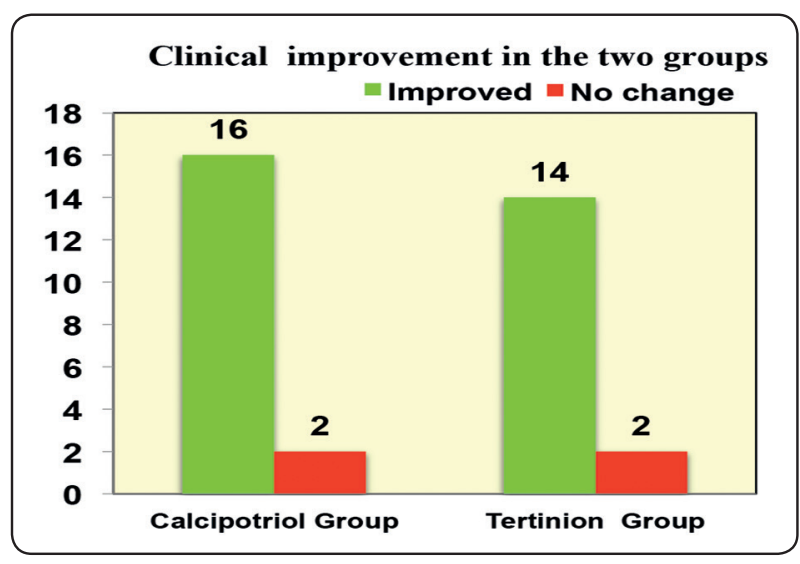

Fig. (1): Comparison between the two studied groups in number of cases improved and those with no visible change

TABLE (1) Comparison in improvement in clinical score between groups I and II at 4 weeks

\begin{tabular}{|c|c|c|c|c|c|c|}
\hline \multirow{2}{*}{4} & \multicolumn{2}{|c|}{ Calcipotriol Group } & \multicolumn{2}{|c|}{ Tretinoin Group } & \multirow{2}{*}{ Z } & \multirow{2}{*}{ P-Value } \\
\cline { 2 - 6 } & Number & $\%$ & Number & $\%$ & 1.25 & 0.2119 \\
\hline 0: Total resolution & 5 & $25 \%$ & 2 & $30 \%$ & \multicolumn{2}{|c|}{ Equal Percentage } \\
\hline 1:Moderate resolution & 6 & $30 \%$ & 6 & $30 \%$ & 0.35 & 0.7233 \\
\hline 2: Minimal change & 5 & $25 \%$ & 6 & $10 \%$ & \multicolumn{2}{|c|}{ Equal Percentage } \\
\hline 3: No visible change. & 2 & $10 \%$ & 2 & & $10 \%$ & \\
\hline
\end{tabular}




\section{Results for biochemical markers}

On comparing pre and post treatment values of each variable within Group I (Calcipotriol), this comparison revealed that the mean and SD values of MMP-9 level $(\mu \mathrm{g} / \mathrm{L})$ pre-and post-treatment was $7.50( \pm 0.88)$ and $4.71( \pm 0.91)$ respectively with a mean difference of $(-2.79)$. Therefore, there is a statistically highly significant reduction in MMP9 level post-treatment with $\mathrm{P}$-value $(<0.001)$. The mean and SD values of TGF- $\beta$ (ng/ml) level pre-and post-treatment was $18.89( \pm 2.44)$ and $14.30( \pm 2.91)$ respectively with a mean difference of (-4.59). Therefore, there is also a statistically highly significant reduction in TGF- $\beta$ level post-treatment with P-value $(<0.001)$. Regarding IL-6 $(\mathrm{pg} / \mathrm{ml})$ the mean and SD values for pre and post-treatment level was 51.64( $( \pm 9.71)$, and 27.19 $( \pm 7.24)$ respectively with a mean difference of $(-24.45)$.Therefore, there is also a highly significant reduction statistically in IL-6 level post-treatment with P-value $(<0.001)$. Table (2)

On comparing pre and post treatment values of each variable within Group II (Tretinoin) this comparison revealed that the mean and SD values of MMP-9 ( $\mu \mathrm{g} / \mathrm{L})$ level pre- and post-treatment level was $7.72( \pm 0.60)$ and $.87( \pm 0.76)$ respectively with a mean difference of $(-1.86)$.This shows a statistically highly significant reduction in MMP-9 level posttreatment with P-value $(<0.001)$. Same for the mean and SD values of TGF- $\beta(\mathrm{ng} / \mathrm{ml})$ level pre-and post-treatment was $25.16( \pm 4.84)$ and $19.72( \pm 4.80)$ respectively with the mean difference was $(-5.44)$. This denotes that there is also a highly significant reduction in TGF- $\beta$ level post-treatment with P-value $(<0.01)$. Regarding IL-6 (pg/ml) the mean and SD values for its pre- and post-treatment level was $50.62( \pm 10.99)$ and $33.31( \pm 8.31)$ respectively with the mean difference was (-17.31). Therefore, there is also a significant reduction in IL-6 level post-treatment with $\mathrm{P}$-value $(<0.05)$. Table (2)

Table (2) shows comparison in pre-and posttreatment values of the three biological markers (MMP-9, TGF- $\beta$, and IL-6) between the two groups.

Group I (calipotriol) revealed highly significant reduction $(\mathrm{P}<0.001)$ in post-treatment level of MMP-9 and IL-6 compared to Group II (tretinoin). On the other hand, there was non-significant difference $(\mathrm{P}>0.05)$ between the two groups posttreatment values of TGF- $\beta$.

TABLE (2) Comparison in pre-and post-treatment values of the three biological markers (MMP-9, TGF- $\beta$ and IL-6) between the two studied groups.

\begin{tabular}{|c|c|c|c|c|c|c|c|c|c|c|}
\hline & & $\mathbf{N}$ & Mean & $\begin{array}{c}\text { Std. } \\
\text { Deviation }\end{array}$ & $\begin{array}{c}\text { Mean } \\
\text { Difference }\end{array}$ & $\begin{array}{l}\text { Std. Error } \\
\text { Difference }\end{array}$ & $\mathbf{t}$ & df & Probability & \\
\hline \multirow{2}{*}{$\begin{array}{l}\text { MMP-9 } \\
(\mathbf{u g} / \mathrm{L})\end{array}$} & Group I (Calcipotriol) & 20 & -2.79 & 0.92 & \multirow[t]{2}{*}{-0.93} & \multirow[t]{2}{*}{0.26} & \multirow[t]{2}{*}{-3.65} & \multirow[t]{2}{*}{38} & \multirow[t]{2}{*}{0.00078} & \multirow{2}{*}{$\begin{array}{c}\mathrm{P}<0.001 \text { Highly } \\
\text { Significant }\end{array}$} \\
\hline & Group II (Tretinoin ) & 20 & -1.86 & 0.67 & & & & & & \\
\hline \multirow{2}{*}{$\begin{array}{l}\text { TGF }-\beta \\
(\mathbf{n g} / \mathbf{m l})\end{array}$} & Group I (Calcipotriol) & 20 & -4.59 & 0.98 & \multirow[t]{2}{*}{0.84} & \multirow[t]{2}{*}{0.57} & \multirow[t]{2}{*}{1.49} & \multirow[t]{2}{*}{38} & \multirow[t]{2}{*}{0.14414} & \multirow{2}{*}{$\begin{array}{c}\text { P>0.05 Non } \\
\text { Significant }\end{array}$} \\
\hline & Group II (Tretinoin ) & 20 & -5.44 & 2.33 & & & & & & \\
\hline \multirow{2}{*}{$\begin{array}{c}\text { IL-6 } \\
\text { (pg/ml) }\end{array}$} & Group I (Calcipotriol) & 20 & -24.45 & 6.67 & \multirow[t]{2}{*}{-7.14} & \multirow[t]{2}{*}{2.20} & \multirow[t]{2}{*}{-3.25} & \multirow[t]{2}{*}{38} & \multirow[t]{2}{*}{0.00245} & \multirow{2}{*}{$\begin{array}{c}\text { P }<0.01 \text { Highly } \\
\text { Significant }\end{array}$} \\
\hline & Group II (Tretinoin ) & 20 & -17.31 & 7.23 & & & & & & \\
\hline
\end{tabular}




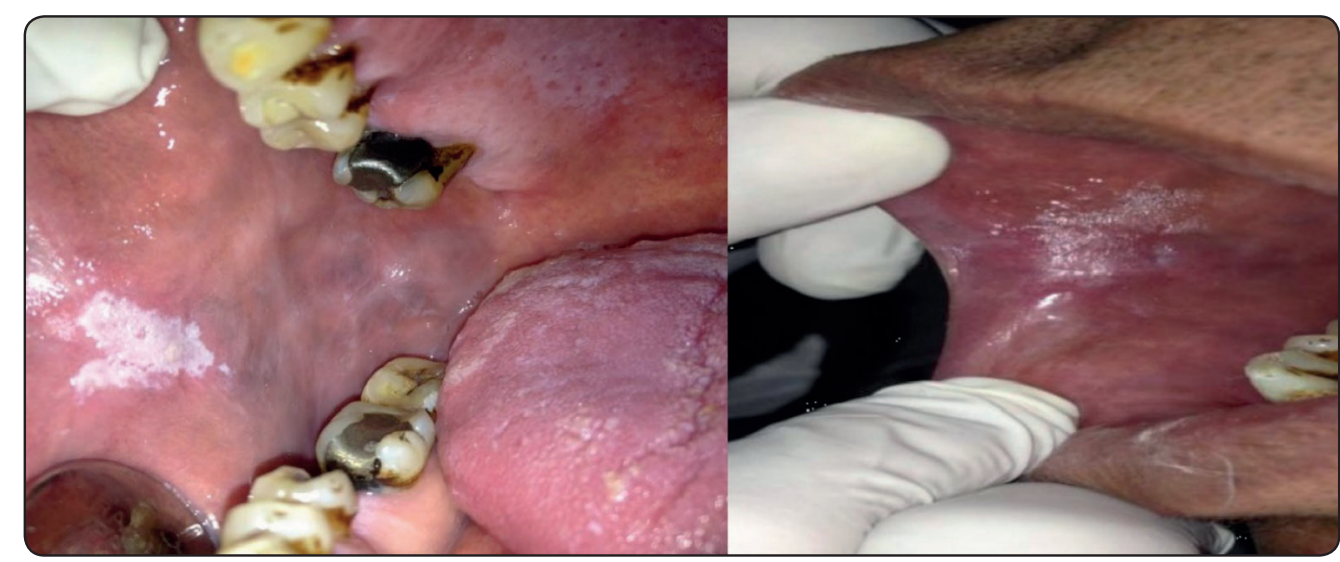

Clinical Photograph of 47 years old male patient with oral leukoplakia before and after treatment with topical calcipotriol

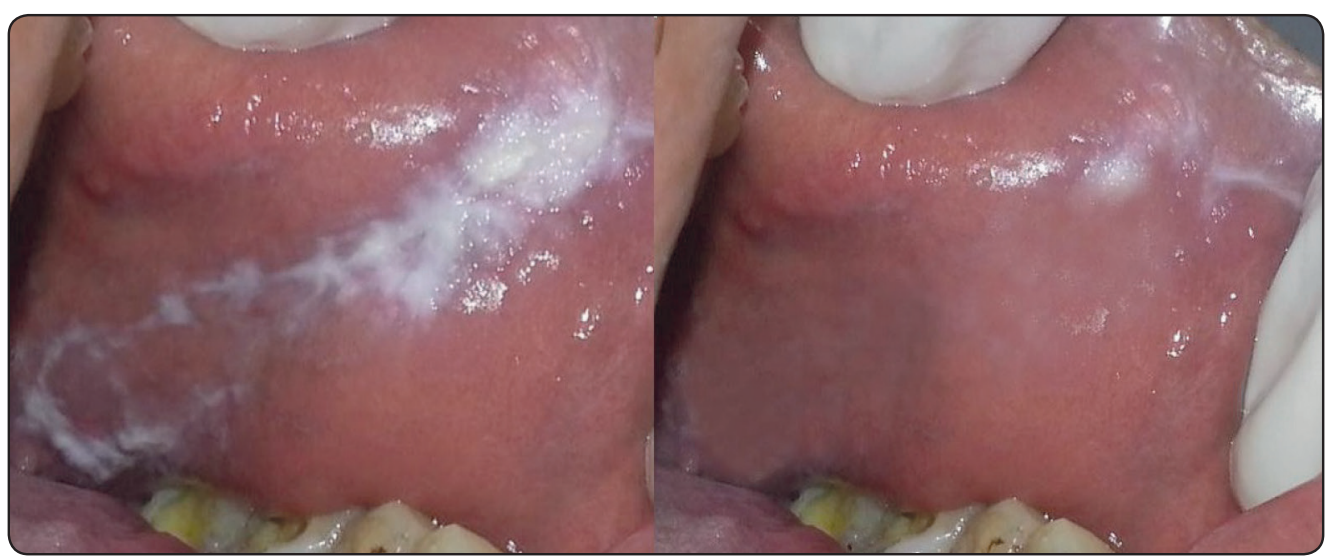

Clinical photograph showing a case of 49 years male patient with oral leukoplakia before and after treatment with topical tretinoin

\section{DISCUSSION}

The aim of this clinical trial was to compare the effectiveness of topical calcipotriol versus topical tretinoin in treatment of oral leukoplakia regarding changes in clinical score as well as salivary IL-6, TGF- $\beta$ and MMP-9 level.

Patients were chosen to be systemically healthy according to modified Cornell index ${ }^{(37)}$. Periodontitis patients were excluded since IL-6, TGF- $\beta$ and MMP9 have shown to play role in the pathogenesis of periodontitis. Rai et al., ${ }^{(50,51)}$ concluded that MMP9 may serve as biomarkers of periodontal disease and aid in early detection of periodontitis. Diabetic patients and those with coronary heart diseases were also excluded from the study. Maxwell et al., (52) demonstrated that MMP-9 and their inhibitors are integral to the vascular changes of atheroma and MMP-9 level is raised in diabetes. Furthermore, hepatic patient were also excluded since the use of vitamin A related compounds have demonstrated liver damage ${ }^{(53,50,51,39,38)}$.

Additionally, cases with hypercalcemia, hypercalciuria, urolithiasis, parathyroid disease, disorders of calcium metabolism, concomitant use of vitamin $\mathrm{D}$ or calcium or any other drug that can affect calcium homeostasis were all excluded since they are contraindicated for treatment with calcipotriol ${ }^{(40)}$. Although the risk of embryopathies associated to topical retinoids is considered low, 
their use during pregnancy is not recommended because their risk/benefit ratio remains questionable. Therefore, Pregnancy and lactation were also excluded ${ }^{(54)}$.

Location of lesions in this study was readily accessible for topical application of drug since lesions in inaccessible areas like soft palate were excluded.

Unfortunately, though many leukoplakias in previous studies have regressed or resolved during systemic treatment with vitamin A analogues, toxicity and risk of teratogenecity has been the main limiting factors in the use of systemic retinoids. It is possible that the local application of retinoic acid results in a higher concentration of the substance directly in the target tissue. For this reason, in this study the use of topical preparations was preferred ${ }^{(23,55)}$.Topical preparation could adhere well to oral mucosa and provide transport medium of active drug together with reasonable exposure time since it was prepared in adhesive vehicle (carboxymethylcellulose).

Dosage of tretinoin cream $(0.05 \%)$ used as twice daily was in accordance with other studies that used tretinoin in treatment of oral leukoplakia $(47,23,56,48)$. Dosage of calcipotriol preparation $(5 \mu \mathrm{g} / \mathrm{g})$ $(0.005 \%)$ twice daily was similar to dosage reported by Shahzad et al. ${ }^{(40)}$ reviewing the use of topical calcipotriol in dermatology.

In the present study the follow up period was chosen to be 4 weeks in accordance with Günther, (57) who reported improvement in lesions in this period of time. This period probably correspond to the time required for the renewal of the epithelium.

Salivary testing has the advantage of being a non-invasive alternative to serum testing, can be an effective modality for diagnosis and prognosis predicting of oral cancer and premalignant lesions as well as for monitoring the patient's post-therapy status ${ }^{(58)}$.
This study utilized ELISA technique in order to assess the level of IL-6, TGF- $\beta$ and MMP-9 in whole unstimulated saliva. The ELISA system is cited as the most sensitive, well-established, and widely available protein-based testing platform for the detection of specific proteins in body fluids or tissue ${ }^{(59)}$. ELISA-based techniques seem more costeffective because they are simple to perform and inexpensive. It also allows for antigen detection using extremely small samples ${ }^{(60)}$.

Result of the present study showed that there was a statistically significant improvement in clinical scores within tretinoin group with total resolution in $30 \%$ of cases, moderate resolution in $30 \%$ of patients and minimal change in $10 \%$. So patients showing any improvement constitutes $70 \%$ while those with no visible change are only $10 \%$.These percentages were significantly higher at 4 weeks than those at 2 weeks of treatment period.

The clinical results in the tretinoin group were in line with those of Shah et al. ${ }^{(61)}$ who performed a 6-month trial using isotretinoin lozenges in patients with oral leukoplakia. They evaluated clinically thinning of the leukoplakia and a reduction in the white surface. In patients who completed trial, (27\%) showed complete visible clinical response, while $(80 \%)$ of patients documented remission.

Epstein and Gorsky, ${ }^{(47)}$ used $0.05 \%$ tretinoin gel that was applied topically 4 times per day for the management of non-malignant oral white lesions. Complete clinical remission was reported in (27\%) of patients. However, partial response was noted in $54 \%$ of patients. Their results were in accordance with results of the present study were they used same concentration but in the form of gel.

Piattelli et al., (27) during the assessment of $0.1 \%$ isotretinoin gel applied 3 times per day in oral leukoplakia for 4 months a complete response was noted in $(10 \%)$ of patients, although $(90 \%)$ of patients experienced a reduction in size of at least $50 \%$, representing a partial response. Tete et al., ${ }^{(62)}$ 
noted complete remission in (21.5\%) of patients with topical $0.1 \%$ isotretinoin, a marked improvement (a reduction in size $50 \%$ ) was achieved in $(78.5 \%)$ of patients in 4 months of treatment.

Considering the assumption that topical tretinoin could be a potential alternative for surgical removal in some cases of oral leukoplakia, Starzyńska et al. ${ }^{(48)}$ performed a study which included patients having oral leukoplakia, compared the effectiveness of $0.05 \%$ topical tretinoin cream with surgical and cryosurgical treatment. In over $77 \%$ of patients treated with tretinoin, total improvement was observed after 4 weeks of treatment time. This percentage is consistent with results in the present study in which $70 \%$ of patients treated with tretinoin showed total improvement in same period of time (4weeks).

Data from the current study showed that there was a statistically significant improvement in clinical scores within calcipotriol group with total resolution in $25 \%$ of cases, moderate resolution in $30 \%$ of patients and minimal change in $25 \%$. So patients showing any improvement constitutes $80 \%$ while those with no visible change were only 10 $\%$.These percentages were significantly higher at 4 weeks than those of 2 weeks of treatment period.

Moreover, in the present clinical trial by 4 weeks, the percentage of improved cases was slightly higher in calcipotriol than tretinoin group with nonsignificant difference between groups.

These results were in accordance with an open trial conducted by Femiano et al., ${ }^{(23)}$ to compare the clinical efficacy of topical calcipotriol $(50 \mathrm{mg} / \mathrm{g}$ ) with tretinoin cream $(0.05 \%)$ in the therapy of hyperkeratotic oral lesions (leukoplakia). Their results showed that in 2 weeks, keratotic lesions in both study groups had substantially regressed, with leveling of hyperkeratotic surfaces, softening and an attenuation of the whiteness. By the fifth week, $80 \%$ of patients in both groups showed complete clinical resolution of lesions in both calcipotriol and tretinoin groups that was consistent with results in the present study.

Femiano et al., (23) suggested that topical calcipotriol is as effective in the treament of oral leukoplakia as is topical tretinoin. These suggestion was confirmed by results of the present study. Modulation of cellular differentiation and proliferation by compounds such as some of the newer retinoids and calipotriol offers the possibility for the therapeutic prevention, reversal, or arrest of carcinogenesis.

Among many factors included in etiopathogenesis of PMDs as leukoplakia, MMP-9 plays a fundamental role in tumor biology. Stott-Miller et al. ${ }^{(63)}$ stated that salivary MMP-9 is a robust diagnostic biomarker of malignant transformation. Detection of MMP-9 proteins in saliva in particular may provide a promising means to detect and monitor PMDs post-therapy status non-invasively.

Results of the present study indicated highly significant reduction in MMP-9 $(\mu \mathrm{g} / \mathrm{L})$ level $(\mathrm{P}<$ 0.001 ) in tretinoin treated group at the end of the study period. Results were in accordance with Nguyen et al. ${ }^{(64)}$, Papi et al. ${ }^{(65)}$; Jalian et al. ${ }^{(66)}$; Yang et al. ${ }^{(67)}$. In their in vitro investigations, they found that ATRA (tretinoin) might down regulate the expression of MMP-9. Contrarily, Darmanin et al. ${ }^{(68)}$ reported that ATRA could increase the expression of MMP-9. Therefore, available evidences were controversial due to disagreement between studies ${ }^{\left({ }^{(69)} \text {. }\right.}$

Results of the present study indicated highly significant reduction in salivary MMP-9 $(\mu \mathrm{g} / \mathrm{L})$ level in calcipotriol treated group $(\mathrm{P}<0.001)$. Results were in accordance with Meephansan et al. ${ }^{(70)}$ who investigated whether calcipotriol could suppress the expression of MMP-9 in a human squamous cell carcinoma (SCC) cell line. They found that calcipotriol suppressed the production of MMP-9 mRNA and proteins significantly, in a dosedependent manner. 
In the present study, there was highly significant reduction in MMP-9 level after both tretinoin and calcipotriol treatment. However, there was a statistically significant higher reduction of salivary MMP-9 level in calcipotriol than tretinoin treated group. This support the suggestion that calcipotriol could be potential alternative to tretinoin in management of premaligant lesions.

Results of the present study indicated highly significant reduction in TGF- $\beta$ level $(\mathrm{P}<0.001)$ in calcipotriol treated group. Results of the present study also indicated highly significant reduction in salivary TGF- $\beta$ level in tretinoin treated group (P $<0.01)$ at the end of the study period. When the reduction in TGF- $\beta$ level was compared between the two groups no significant difference was found $(\mathrm{P}>0.05)$.

Wagner et al ${ }^{(71)}$ analysed TGF- $\beta$ expression in a spectrum of samples that included normal mucosa, leukoplakia with or without dysplasia, and OSCC and reported that OSCC exhibited the higher levels of expression of TGF- $\beta$ than leukoplakia and normal mucosa samples and suggested that TGF- $\beta$ modifications are associated with the progression of oral carcinogenesis, based on the gradual increase in the expression of TGF- $\beta$ between the normal mucosa, leukoplakia, then the carcinoma cases.

Moreover, previous reports have demonstrated that TGF- $\beta$ stimulation induces severe epithelial hyperplasia in oral mucosa and increases the proliferation rate of oral cancer cells ${ }^{(\mathbf{1 9})}$, In the same line another study of TGF- $\beta$ receptor II has indicated that its down-regulation is an early event in oral carcinogenesis, which may occur in the loss of TGF- $\beta$ mediated inhibition, thereby facilitating progression of precancerous lesions to SCC ${ }^{(72)}$.

All these data supports the hypothesis that during the process of oral carcinogenesis, the TGF- $\beta$ signalling pathway loses the capacity to inhibit cell growth and begins to enhance tumor progression indicating that TGF- $\beta$ is highly active in this type of oral lesions and may represent a valuable therapeutic target, and that the development of TGF- $\beta$ inhibitors for cancer therapy is under progress ${ }^{(71)}$.

Taking that under consideration together with the results of the present study showing the effect of topical application of both calcipotriol and tretinoin that has led to a highly significant reduction in TGF- $\beta$ level at the end of treatment period illustrating the inhibitory effect they have on TGF- $\beta$ which could in turn contribute to the possible arrest or slowing of the progression of tissue change that may occur in leukoplakia lesions which is further confirmed with the recorded clinical improvement in most cases. This also provides more evidence that using TGF- $\beta$ as a therapeutic target in leukoplakia is a promising strategy not only for improving the case clinically but also to reduce the possibility of occurrence of malignant transformation of one of the most common PMDs of the oral cavity.

IL-6 is an NF- $x$ B dependent cytokine produced by inflammatory cells as well as tumor cells ${ }^{(73)}$. As NF- $x$ B-dependent cytokine, IL-6 levels were found to be significantly elevated in saliva of patients with potentially malignant lesions and oral squamous cell carcinoma ${ }^{(74)}$. It has been found that the IL-6 level in saliva was three to four times more than that in serum. For all the previously mentioned facts, the potential value of IL- 6 as a diagnostic marker of malignant transformation was considered ${ }^{(75)}$.

The results of the present study showed that IL-6 salivary level was significantly reduced after topical application of calcipotriol. To the best of our knowledge, this is the first clinical trial to evaluate the effect of topical calcipotriol and topical tretinoin used for the treatment of oral leukoplakia on salivary IL-6 level, this makes comparison with similar studies not possible. Calcipotriol shares the antiinflammatory attributes of vitamin D, and is used as a topical treatment in many cutaneous lesions particularly psoriasis. The effects of calcipotriol are likely due primarily to its anti-proliferative effects on human keratinocytes ${ }^{(76,77)}$, with the drug's ability 
to suppress secretion of pro-inflammatory cytokines such as IL-1, IL-6, IL-8, and IL-18 from both human and murine keratinocyte ${ }^{(78)}$. This explains the highly significant reduction in IL-6 level in calcipotriol treated group.

There was also a significant reduction in salivary IL-6 in tretinoin- treated group. Studies showed that tretinoin has a direct and indirect inhibitory effect on IL-6. The human epidermoid carcinoma cell line A431 was cultured with phorbol 12-myristate 13-acetate, which stimulates release of the proinflammatory cytokine IL-6 from this cell line. Addition of tretinoin to this system inhibited very potently the release of IL-6 ${ }^{(79)}$.

TNF- $\alpha$, which is multifunctional cytokine that can induce a broad range of secondary proinflammatory effects is produced in part by human keratinocyte ${ }^{\mathbf{8 0})}$. It can activate cell adhesion molecules; upregulates prostaglandins, and can induce the release of other cytokines, such as IL-1, IL-6, IL-8, and granulocyte macrophage colony-stimulating factor ${ }^{(81)}$. Brailo et al. ${ }^{(15)}$ found that patients with oral leukoplakia has significantly higher levels of salivary TNF- $\alpha$ compared to healthy individuals. Several studies have shown that tretinoin is a potent inhibitor of TNF- $\alpha$ production ${ }^{(82,83,44)}$ which leads to the reduction in IL-6.

Results of the present study showed that topical calcipotriol produced more significant reduction in salivary IL-6 than do topical tretinoin. Therefore, IL-6 has shown to be an important biomarker for predicting therapeutic responses ${ }^{(75)}$.

From the previously mentioned results we could conclude that topical calcipotriol is as effective as topical tretinoin in the clinical improvement of oral leukoplakia. Moreover, both treatments produced significant reduction in salivary levels of MMP9, IL-6 and TGF- $\beta$, which may help monitoring the progression of potentially malignant lesions into carcinoma. Furthermore, this inhibitory effect of both therapeutic agents on the three important cytokines indicated that they can reduce the possibility of occurrence of malignant transformation in oral potentially malignant lesions. Taking into consideration that in the present study calcipotriol treatment resulted in more cases with clinical improvement than tretinoin and that it also resulted in greater reduction of MMP-9, IL-6 levels than tretinoin indicating that calcipotriol is not only as effective as tretinoin but could even be considered a promising therapeutic alternative with fewer side effects.

\section{REFERENCES}

1. Masthan KM, Babu NA, Sankari SL, Priyadharsini C (2015).Leukoplakia: A short review on malignant potential . J Pharm Bioallied Sci. Apr; 7(Suppl 1):S165-6.

2. Antony G, Sreenivasan BS, Sunil S, Varghese SS, Thomas J, Gopakumar D, et al (2011). Potentially malignant disorders of oral cavity. Oral Maxillofac Pathol J.2:95-100.

3. Petti S. (2003). Pooled estimate of world leukoplakia prevalence: A systematic review. Oral Oncol. 39:770-80.

4. Amagasa T, Yamashiro M, Uzawa N. (2011). Oral premalignant lesions: from a clinical perspective . Int $\mathrm{J}$ Clin Oncol. Feb; 16(1):5-14.

5. Van der Waal I. (2009). Potentially malignant disorders of the oral and oropharyngeal mucosa; terminology, classification and present con $\neg$ cepts of management. Oral Oncol. 2009; 45:317-23.

6. Van der Waal I, Schepman KP, Van der Meij EH, Smeele LE (1997). Oral leukoplakia: a clinicopathological review. Oral Oncol. 33:291-301.

7. Schepman KP, van der Meij EH, Smeele LE, van der Waal (1998). . I. Malignant transformation of oral leukoplakia: a follow-up study of a hospital-based population of 166 patients with oral leukoplakia from The Netherlands OralOncol. 34:270-5.

8. Holmstrup P, Vedtofte P, Reibel J, Stoltze K (2006). Longterm treatment outcome of oral premalignant lesions. Oral Oncol.42:461-74.

9. Brailo V1, Vucicevic-Boras V, Lukac J, Biocina-Lukenda D, Zilic-Alajbeg I, Milenovic A, Balija M. (2012). Salivary and serum interleukin 1 beta, interleukin 6 and tumor necrosis factor alpha in patients with leukoplakia and oral cancer . Med Oral Patol Oral Cir Bucal. Jan 1;17(1):e10-5. 
10. Hodge. D. R., Hurt, E. M., Farrar, W. L. (2005). The role of IL-6 and STAT3 in inflammation and cancer .Eur. J. Cancer 41, 2502-2512.

11. Powis G, Kirkpatrick L (2004) Hypoxia inducible factor1alpha as a cancer drug target. Mol Cancer Ther 3:647654.

12. Niu G, Briggs J, Deng J, Ma Y, Lee H, Kortylewski M, Kujawski M, Kay H, Cress WD, Jove R, Yu H (2008) Signal transducer and activator of transcription 3 is required for hypoxia-inducible factor-1alpha RNA expression in both tumor cells and tumor-associated myeloid cells. Mol Cancer Res 6:1099-1105.

13. Hirano T, Ishihara K, Hibi M (2000) Roles of STAT3 in mediating the cell growth, differentiation and survival signals relayed through the IL-6 family of cytokine receptors. Oncogene 19:2548-2556.

14. Barton BE, Murphy TF, Adem P, Watson RA, Irwin RJ, Huang HF (2001) IL-6 signalling by STAT3 participates in the change from hyperplasia to neoplasia in NRP-152.

15. Brailo V, Vucićević-Boras V, Cekić-Arambasin A, Alajbeg IZ, Milenović A, Lukac J (2006). The significance of salivary interleukin 6 and tumor necrosis factor alpha in patients with oral leukoplakia. Oral Oncol. Apr; 42(4):370-3.

16. Shirai H, ueno E, Osaki M, Tatebe S, Ito H, Kaibara N (1995): Expression of growth factors and their receptors in human early colorectal carcinomas. Immunohistochemical study. Anticancer Res 15:2889-2894.

17. Donnelly MJ, Patel V, Yeudall WA, Game SM, Scully C, Prime SS (1993). Autocrine production of TGF-alpha and TGF-beta during tumour progression of rat oral keratinocytes. Carcinogenesis. May; 14(5):981-5.

18. Vivian P. Wagner, Paula R. Cardoso, Jean N. dos Santos, Luise Meurer, Pablo A. Vargas, Felipe P. Fonseca, Vinicius C. Carrard, * and Manoela D. Martins (2016). Immunohistochemical Study of TGF- $\beta 1$ in Oral Leukoplakia and Oral Squamous Cell Carcinoma: Correlations between Clinicopathologic Factors and Overall Survival. Appl Immunohistochem Morphol .

19. Chen MF, Wang WH, Lin PY, et al (2012). Significance of the TGF-B IL-6 axis in oral cancer. Clin Sci (Lond). 122:459-472.

20. Venugopal A1, Uma Maheswari TN1 (2016). Expression of matrix metalloproteinase-9 in oral potentially malignant disorders: A systematic review. J Oral Maxillofac Pathol. Sep-Dec;20(3):474-479.
21. Tochowicz,A., Maskos, K., Huber, R., Oltenfreiter, R., Dive, V., Yiotakis, A., Zanda, M., et al. (2007). Crystal structures of MMP-9 complexes with five inhibitors: contribution of the flexible Arg424 side-chain to selectivity. Journal of molecular biology, 371(4), 989-1006.

22. Bahar-Shany, K., Ravid, a., and Koren, R. (2010), Upregulation of MMP-9 production by TNF?? in keratinocytes and its attenuation by vitamin D. Journal of Cellular Physiology, 222(3), 729-737.

23. Femiano, F., Gombos, F., Scully, C., Battista, C., Belnome, G., and Esposito, V. (2001). Oral leukoplakia: open trial of topical therapy with calcipotriol compared with tretinoin. International journal of oral and maxillofacial surgery, 30(5), 402-406.

24. Reibel, J. (2003). Prognosis of oral pre-malignant lesions: significance of clinical, histopathological, and molecular biological characteristics. Critical reviews in oral biology and medicine : an official publication of the American Association of Oral Biologists, 14(1), 47-62.

25. Epstein, J. B., Gorsky, M., Wong, F. L. W., and Millner, A. (1998). Topical bleomycin for the treatment of dysplastic oral leukoplakia. Cancer, 83(4), 629-634.

26. Olson, J.A. (1999). Carotenoids and human health. Archivos latinoamericanos de nutrición, 49(3 Suppl 1), 7S-11S.

27. Piattelli, A., Fioroni, M., Santinelli, A., and Rubini, C. (1999). bcl-2 expression and apoptotic bodies in 13-cis-retinoic acid (isotretinoin)-topically treated oral leukoplakia: a pilot study. Oral Oncology, 35(3), 314-320.

28. Gorsky, M., and Epstein, J. B. (2002). The effect of retinoids on premalignant oral lesions: Focus on topical therapy. Cancer, 95(6), 1258-1264.

29. Lippman, S. M., Lee, J. J., Martin, J. W., El-Naggar, A. K., Xu, X., Shin, D. M., Thomas, M., et al. (2006). Fenretinide activity in retinoid-resistant oral leukoplakia. Clinical Cancer Research, 12(10), 3109-3114.

30. Petruzzi, M., Lucchese, A., Lajolo, C., Campus, G., Lauritano, D., and Serpico, R. (2013). Topical retinoids in oral lichen planus treatment: An overview. Dermatology, 226(1), 61-67.

31. Silveira, E. R., Naves, M. M., Vannucchi, H., Jordão Júnior, A.A., Dagli, M. L., and Moreno, F. S. (2001). Vitamin A and all-trans and 9-cis retinoic acids inhibit cell proliferation during the progression phase of hepatocarcinogenesis in Wistar rats. Nutrition and cancer, 39(2), 244-251. 
32. Orlandi, M., Mantovani, B., Ammar, K., Avitabile, E., Dal Monte, P., and Bartolini, G. (2003). Retinoids and cancer: Antitumoral effects of ATRA, 9-cis RA and the new retinoid IIF on the HL-60 leukemic cell line. Medical Principles and Practice, 12(3), 164-169.

33. Dutta, A., Sen, T., and Chatterjee, A. (2010). Alltrans retinoic acid (ATRA) downregulates MMP-9 by modulating its regulatory molecules. Cell Adhesion and Migration, 4(3), 409-418.

34. Díaz, L., Díaz-Muñoz, M., García-Gaytán, A., and Méndez, I. (2015). Mechanistic Effects of Calcitriol in Cancer Biology. Nutrients, 7(6), 5020-5050.

35. Bertolini, D.L., Araujo, P.R., Silva, R.N.(1999). Immunomodulatory effects of vitamin $\mathrm{D}$ analogue KH1060 on an experimental skin transplantation model. Transplant Proc. 31, 2998-9.

36. Leyssens, C., Verlinden, L., and Verstuyf, A. (2014). The future of vitamin D analogs. Frontiers in Physiology, 122(5), 1-18.

37. Brightman, V. J., (1994). Rational procedure for diagnosis and medical risk assessment. In: Lynch MS, Brightman VJ, Greenberg MS. Bercket's Oral Medicine. 9th ed. Lippincott Co. Philadelphia. 729-763.

38. Silosi, I., Cojocaru, M., Foia, L., Boldeanu, M. V., Petrescu, F., Surlin, P., and Biciusca, V. (2015). Significance of Circulating and Crevicular Matrix Metalloproteinase-9 in Rheumatoid Arthritis-Chronic Periodontitis Association. Journal of Immunology Research, 6.

39. Rathnayake, N., Gustafsson, A., Norhammar, A., Kjellström, B., Klinge, B., Rydén, L., Tervahartiala, T., et al. (2015). Salivary Matrix Metalloproteinase- 8 and -9 and Myeloperoxidase in Relation to Coronary Heart and Periodontal Diseases: A Subgroup Report from the PAROKRANK Study (Periodontitis and Its Relation to Coronary Artery Disease). Plos One, 10(7), e0126370.

40. Shahzad, A., Shahzad, M., and Khurshid, K. (2006). Topical calcipotriol in dermatology. Journal of Pakistan Association of Dermatologists, 104-107.

41. Volz, T., Caroli, U., Lüdtke, H., Bräutigam, M., KohlerSpäth, H., Röcken, M., and Biedermann, T. (2008). Pimecrolimus cream $1 \%$ in erosive oral lichen planus - A prospective randomized double-blind vehicle-controlled study. British Journal of Dermatology, 159(4), 936-941.

42. Warnakulasuriya, S., Johnson, N. W., and Van Der Waal, I. (2007). Nomenclature and classification of potentially malignant disorders of the oral mucosa. Journal of Oral Pathology and Medicine, 36(10), 575-580.
43. Neville, B., Damm, D., Allen, C., and Bouquot.(2009). Oral and Maxillofacial Pathology, Saunders/Elsevier, St. Louis, Mo, USA, 3rd edition.

44. Liu, W., Shi, L. J., Wu, L., Feng, J. Q., Yang, X., Li, J., Zhou, Z. T., et al. (2012). Oral cancer development in patients with leukoplakia - clinicopathological factors affecting outcome. PLoS ONE, 7(4), 1-7.

45. Brouns, E.R., Baart, J.A., Bloemena, E., Karagozoglu, H., van der Waal I.(2013).The relevance of uniform reporting in oral leukoplakia: definition, certainty factor and staging based on experience with 275 patients. Medicina Oral, Patologia Oral y Cirugia Bucal, 18(1), 19-26.

46. Wall, A., Poyner, T., and Menday, A. (1998). A comparison of treatment with dithranol and calcipotriol on the clinical severity and quality of life in patients with psoriasis. British Journal of Dermatology, 139(6), 1005-1011.

47. Epstein, J. B and Gorsky, M. (1999). Topical application of vitamin A to oral leukoplakia: A clinical case series. Cancer, 86(6), 921-927.

48. Starzyńska, A., Pawłowska, A., Renkielska, D., Michajłowski, I., Sobjanek, M., Błażewicz, I., and Włodarkiewicz, A. (2015). Estimation of oral leukoplakia treatment records in the research of the Department of Maxillofacial and Oral Surgery, Medical University of Gdansk. Advances in Dermatology and Allergology, 2, 114-122.

49. Nagler, R. M., Lischinsky, S., Diamond, E., Klein, I., and Reznick, a Z. (2001). New insights into salivary lactate dehydrogenase of human subjects. The Journal of laboratory and clinical medicine, 137(5), 363-9.

50. Rai, B., Kharb, S., Jain, R., and Anand, S. C. (2008). Biomarkers of periodontitis in oral fluids. Journal of oral science, 50(1), 53

51. Rai, B., Kaur, J., Jain, R., and Anand, S. C. (2010). Levels of gingival crevicular metalloproteinases-8 and -9 in periodontitis. Saudi Dental Journal, 22(3), 129-131.

52. Maxwell, P.R., Timms, P.M., Chandran, S., Gordon, D.(2001). Peripheral blood level alterations of TIMP1, MMP-2 and MMP-9 in patients with type 1 diabetes. Diabetic medicine: a journal of the British Diabetic Association.18 (10):777-80.

53. Górska, R., and Nȩdzi-Góra, M. (2006). The effects of the initial treatment phase and of adjunctive low-dose doxycycline therapy on clinical parameters and MMP-8, MMP-9, and TIMP-1 levels in the saliva and peripheral blood of patients with chronic periodontitis. Archivum Immunologiae et Therapiae Experimentalis, 54(6), 419-426. 
54. Panchaud, A., Csajka, C., Merlob, P., Schaefer, C., Berlin, M., De Santis, M., Vial, T., et al. (2012). Pregnancy Outcome Following Exposure to Topical Retinoids: A Multicenter Prospective Study. Journal of Clinical Pharmacology, 52, 1844-1851.

55. Piattelli, A., Carinci, F., Iezzi, G., Perrotti, V., Goteri, G., Fioroni, M., and Rubini, C. (2007). Oral lichen planus treated with 13-cis-retinoic acid (isotretinoin): Effects on the apoptotic process. Clinical Oral Investigations, 11(3), 283-288.

56. Kini, G., Nagaratna, D., and Saha, A. (2011). Therapeutic Management of Oral Lichen Planus : A Review for the Clinicians. world journal of dentistry, 2(3), 249-253.

57. Günther, S. H. (1973). Vitamin A acid in treatment of oral lichen planus. Archives of dermatology, 107(2), 277.

58. Nagler, R., Bahar, G., Shpitzer, T., and Feinmesser, R. (2006). Concomitant analysis of salivary tumor markers - A new diagnostic tool for oral cancer. Clinical Cancer Research, 12(13), 3979-3984.

59. Wulfkuhle, J. D., Liotta, L. A., and Petricoin, E. F. (2003). Proteomic applications for the early detection of cancer. Nature reviews. Cancer, 3(4), 267-275.

60. Reyes, C. M., Allen, B. A., Terdiman, J. P., and Wilson, L. S. (2002). Comparison of selection strategies for genetic testing of patients with hereditary nonpolyposis colorectal carcinoma: effectiveness and cost-effectiveness. Cancer, 95(9), 1848-56.

61. Shah, J. P., Strong, E. W., DeCosse, J. J., Itri, L., and Sellers, P. (1983). Effect of retinoids on oral leukoplakia. American journal of surgery, 146(4), 466-470.

62. Tetè, S., Pappalardo, S., Rubini, C., Salini, L., Falco, A., and Perfetti, E. G. (1999). The role of apoptosis and bcl2 protein in topical treatment of oral leukoplakia with isotretinoin. Minerva stomatologica, 48(9), 411-8.

63. Stott-Miller, M., Houck, J. R., Lohavanichbutr, P., Méndez, E., Upton, M. P., Futran, N. D., Schwartz, S. M., et al. (2011). Tumor and salivary matrix metalloproteinase levels are strong diagnostic markers of oral squamous cell carcinoma. Cancer Epidemiology Biomarkers and Prevention, 20(12), 2628-2636.

64. Nguyen, J., Dumont, J., and Bauvois, B. (2006). Comparative effects of interferon-gamma and all- trans retinoic acid on secreted and surface-associated matrix metalloproteinase-9 expression of human monocytes. Cell Mol Biol (Noisy-le-grand), 52(1), 51-58.
65. Papi, A., Bartolini, G., Ammar, K., Guerra, F., Ferreri, A. M., Rocchi, P., and Orlandi, M. (2007). Inhibitory effects of retinoic acid and IIF on growth, migration and invasiveness in the U87MG human glioblastoma cell line. Oncol Rep, 18(4), 1015-1021.

66. Jalian, H. R., Liu, P. T., Kanchanapoomi, M., Phan, J. N., Legaspi, A. J., and Kim, J. (2008). All-trans retinoic acid shifts Propionibacterium acnes-induced matrix degradation expression profile toward matrix preservation in human monocytes. The Journal of investigative dermatology, 128(12), 2777-82.

67. Yang, P., Liu, Z., Wang, H., Tian, J., Li, Y., Zong, Y., and $\mathrm{Qu}$, S. (2009). Enhanced activity of very low density lipoprotein receptor II promotes SGC7901 cell proliferation and migration. Life Sci, 84(13-14), 402-408.

68. Darmanin, S., Chen, J., Zhao, S., Cui, H., Shirkoohi, R., Kubo, N., Kuge, Y., et al. (2007). All-trans retinoic acid enhances murine dendritic cell migration to draining lymph nodes via the balance of matrix metalloproteinases and their inhibitors. J Immunol, 179(7), 4616-4625.

69. Zhou, T.-B., and Qin, Y.-H. (2012). The potential mechanism for the different expressions of gelatinases induced by alltrans retinoic acid in different cells. Journal of Receptors and Signal Transduction, 32(3), 129-133.

70. Meephansan, J., Komine, M., Tsuda, H., and Ohtsuki, M. (2012). Suppressive effect of calcipotriol on the induction of matrix metalloproteinase (MMP)-9 and MMP-13 in a human squamous cell carcinoma cell line. Clinical and Experimental Dermatology, 37(8), 889-896.

71. Wagner VP, Cardoso PR, Santos JN, Meurer L, Vargas PA, Fonseca FP, Carrard VC, and Martis MD (2016). Immunohistochemical study of TGF-B1 in oral leukoplakia and oral squamous cell carcinoma: correlation between clinincopathologic factors and overall survival. Appl Immunohistochem Mol Morphol ;00:000-000.

72. Franchi A, Gallo O, Sardi I, Santucci M (2001) Downregulation of transforming growth factor beta type II receptor in laryngeal carcinogenesis. J. Clin. Pathol 54; 201-204.

73. Wang PL, Ohura K, Fujii T, Oido-Mori M, Kowashi Y, Kikuchi M, Suetsugu Y, Tanaka J (2003) DNA microarray analysis of human gingival fibroblasts from healthy and inflammatory gingival tissues. Biochem Biophys Res Commun 305:970-973.

74. Rhodus NL, Ho V, Miller CS, Myers S, Ondrey F (2005) NFkappa B dependent cytokine levels in saliva of patients 
with oral preneoplastic lesions and oral squamous cell carcinoma. Cancer Detect Prev 29:42-45.

75. Bigbee WL, Grandis JR, Siegfried JM (2007) Multiple cytokine and growth factor serum biomarkers predict therapeutic response and survival in advanced-stage head and neck cancer patients. Clin Cancer Res 13:3107-3108.

76. Reichrath, J., Muller, S. M., Kerber, A., Baum, H. P. and Bahmer, F. A. (1997) Biologic effects of topical calcipotriol (MC 903) treatment in psoriatic skin. J Am Acad Dermatol $36,19-28$.

77. Takahashi, H., Ibe, M., Kinouchi, M., Ishida-Yamamoto, A., Hashimoto, Y. and Iizuka, H. (2003) Similarly potent action of 1,25-dihydroxyvitamin D3 and its analogues, tacalcitol, calcipotriol, and maxacalcitol on normal human keratinocyte proliferation and differentiation. Journal of Dermatological Science 31, 21-8.

78. Kong, J., Grando, S. A. and Li, Y. C. (2006) Regulation of IL-1 family cytokines IL- 1alpha, IL-1 receptor antagonist, and IL-18 by 1,25-dihydroxyvitamin D3 in primary keratinocytes. J Immunol 176, 3780-7.
79. Wauben-Penris PJJ, Cerneus DP, van den Hoven WE, Leuven PJMJ, den Brok JHAM, Hall DWR (1998). Immunomodulatory effects of tretinoin in combination with clindamycin. J Eur Acad Dermatol Venereol.11(suppl 1):S2-S7.

80. Schmidt N, Gans EH (2011). Tretinoin: A Review of Its Anti-inflammatory Properties in the Treatment of Acne. J Clin Aesthet Dermatol. Nov;4(11):22-9.

81. Kuwahara K, Kitazawa T, Kitagaki H, et al (2005). Nadifloxacin, an antiacne quinolone antimicrobial, inhibits the production of proinflammatory cytokines by human peripheral mononuclear cells and normal human keratinocytes. J Dermatol Sci. 38:47-55.

82. Becherel P-A, Mossalai MD, Goff LL (1994). Mechanism of anti-inflammatory action of retinoids on keratinocytes. Lancet. 344(8936):1570-1571.

83. Becherel P-A, Le Goff L, Ktorza S, et al (1996). CD23Mediated nitric oxide synthase pathway induction in human keratinocytes is inhibited by retinoic acid derivatives. J Invest Dermatol. 106:1182-1186. 